\title{
BMJ Open Mindfulness-based cognitive therapy experiences in youth with inflammatory bowel disease and depression: findings from a mixed methods qualitative study
}

\author{
Tatjana Ewais (D) , ${ }^{1,2,3}$ Jake Begun, ${ }^{1,3}$ Maura Kenny, ${ }^{4}$ Alan Headey, ${ }^{3}$ Merilyn Tefay, ${ }^{3}$ \\ Steve Kisely (1D) ${ }^{1}$
}

To cite: Ewais T, Begun J, Kenny M, et al. Mindfulnessbased cognitive therapy experiences in youth with inflammatory bowel disease and depression: findings from a mixed methods qualitative study. BMJ Open 2020;10:e041140. doi:10.1136/ bmjopen-2020-041140

- Prepublication history and additional material for this paper is available online. To view these files, please visit the journal online (http://dx.doi.org/10. 1136/bmjopen-2020-041140)

Received 05 June 2020 Revised 25 August 2020 Accepted 29 September 2020

\section{Check for updates}

(c) Author(s) (or their employer(s)) 2020. Re-use permitted under CC BY-NC. No commercial re-use. See rights and permissions. Published by BMJ.

${ }^{1}$ Mater Clinical School and Princess Alexandra Clinical School, School of Medicine, University of Queensland, Saint Lucia, Queensland, Australia ${ }^{2}$ Faculty of Medicine, Griffith University, Gold Coast, Queensland, Australia ${ }^{3}$ Mater Young Adult Health Centre, Mater Misericordiae Ltd, South Brisbane, Queensland, Australia

${ }^{4}$ Faculty of Health and Medical Sciences, University of Adelaide, Adelaide, South Australia,

Australia

Correspondence to

Dr Tatjana Ewais;

tatjanaewais@gmail.com

\section{ABSTRACT}

Objectives Mindfulness-based cognitive therapy (MBCT) is effective in treating psychosocial comorbidities in inflammatory bowel disease (IBD); however, there have been no qualitative studies of MBCT experiences among youth with IBD. We aimed to examine the experiences of youth with IBD and depression who completed an adapted MBCT group programme, and the impact of common psychotherapy and group factors.

Design This mixed method qualitative study, nested within a randomised controlled trial (RCT) of MBCT for youth with IBD, employed thematic analysis of qualitative data from three focus groups and open-ended survey questions.

Setting The study was conducted in the outpatient department of a tertiary hospital for young adults in Brisbane, Australia.

Participants Out of sixty-four adolescents and young adults recruited to the RCT of MBCT for youth with IBD and depression, 29 completed the MBCT evaluation survey and 19 attended the focus groups.

Results Four key themes emerged: 'connectedness and shared understanding', 'growing in wisdom', 'therapeutic alliance' and 'barriers to mindfulness practice'.

Participants described MBCT experiences as healing and transformative with the themes of connectedness, growing in wisdom and therapeutic alliance laying the foundation for therapeutic change. Main barriers included fatigue, depression, time and travel constraints.

Conclusions The study identified key themes facilitating the process of therapeutic change within the MBCT programme for youth with IBD and elucidated common and group psychotherapy factors underlying the key themes. Participants perceived connecting with peers as essential for learning mindfulness skills which in turn strengthened the connection. Study findings will facilitate interpretation of the results of the RCT of MBCT in youth with IBD and inform the design of future studies of MBCT in this cohort.

Trial registration number ACTRN12617000876392; Results.
Strengths and limitations of this study

- This qualitative study is the first to investigate mindfulness-based cognitive therapy (MBCT) experiences in youth with inflammatory bowel disease.

- It is also the first study that explored the role of common and group therapy factors within MBCT in this cohort.

- Study validity was strengthened by data and investigator triangulation and participant checking.

- One of the researchers conducting thematic analysis also participated in the recruitment and observed focus groups which may have influenced participants' responses and researcher's observations.

- Study findings will help inform the design of future larger studies of MBCT in this patient group.

\section{INTRODUCTION}

\section{Background}

Inflammatory bowel disease (IBD) is a chronic immune-mediated disease of the gastrointestinal tract with frequent extraintestinal manifestations and high rates of comorbid mental health conditions. ${ }^{12}$ Individuals with IBD have two to three times higher rates of depression and anxiety than general population, ${ }^{34}$ and increased rates of fatigue, pain and traumarelated symptoms. ${ }^{5-7}$ There is considerable evidence that mental health comorbidities can worsen the course of IBD, precipitate flares and significantly impair quality of life in individuals with IBD. ${ }^{389}$ There is also increasing evidence supporting the bidirectional interaction between IBD and mental health comorbidities, ${ }^{10}{ }^{11}$ through the microbiome-gut brain axis, ${ }^{12-14}$ mediated by stress, underlying inflammation and other environmental and intrinsic factors. ${ }^{15-17}$

Early recognition and treatment of psychosocial comorbidities within an integrated model of $\operatorname{care}^{18}$ is especially important in youth with IBD, as the peak incidence of IBD 
occurs in adolescence and young adulthood, ${ }^{19}{ }^{20}$ causing interruption in a key developmental stage and impairments in multiple areas of functioning. ${ }^{21}$ Timely and comprehensive interventions in adolescents and young adults (AYAs) with IBD may therefore provide both immediate and long-term improvement in their health, as well as their psychosocial adjustment, relationships, education, employment and other important areas.

\section{Mindfulness-based programmes, inflammatory bowel disease and depression}

Mindfulness-based programmes (MBPs) are therapeutic programmes based on core mindfulness principles and experiential learning through sustained training in formal and informal mindfulness practices. ${ }^{22}$ They are increasingly incorporated in the integrated treatment of IBD as they are effective in treating depression, mitigating stress and improving quality of life, as well as attenuating the underlying immune system abnormalities and disease activity. ${ }^{23-26}$

Mindfulness-based stress reduction and mindfulnessbased cognitive therapy (MBCT) are two MBPs that have a strong evidence base and have been successfully used in the treatment of individuals with IBD. ${ }^{242728}$ The MBCT programme used in this study is an 8-week group mindfulness programme that closely follows the original MBCT curriculum ${ }^{29}$ and has been adapted for both IBD and youth. Modifications include the following: youthfriendly poetry; the role of stress in flares and the gutbrain axis; shortened meditation practices and adapted mindful movement postures to accommodate fatigue and pain and fun postcards to facilitate naming mind states. Although mindfulness interventions have been used successfully in adults with IBD, ${ }^{24} 2830$ there has been only one study exploring feasibility and acceptability of a mindfulness-based group intervention in adolescents with $\mathrm{IBD}^{31}$ and one qualitative study of adult IBD sufferers' perceptions of an MBCT programme. ${ }^{32}$

\section{Common psychotherapy factors and group factors in mindfulness training}

Common psychotherapy factors are defined as therapeutic elements that are present in many therapies and contribute to their benefits and relative therapeutic equivalence. ${ }^{33-35}$ Common examples include the therapeutic alliance, therapy rationale and expectations, enactment of adaptive actions, exposure and sense of mastery. ${ }^{36} 37$ Group factors are key contributors to change in psychotherapeutic, educational and support groups. ${ }^{38-40}$ The following eleven are modified from the work of Yalom: instillation of hope; universality; imparting information; altruism; corrective recapitulation of the primary family unit; development of socialising; imitative behaviours; interpersonal learning; group connection; emotional expression and existential factors. ${ }^{38}$

Common and group psychotherapy factors are closely aligned with key mindfulness principles and attitudinal foundations of non-judging, patience, beginner's mind, trust, non-striving, acceptance and letting go, ${ }^{41}$ and mindfulness itself may be one of the core common factors. ${ }^{42}$ Despite these close links, there has been only one study of common factors in an MBCT programme for headache that used quantitative methodology ${ }^{43}$ and none of group factors. The present mixed methods qualitative study is therefore the first to explore experiences of MBCT in AYAs with IBD and the role of common and group factors in MBCT in this patient group.

\section{Objectives}

The aim of the study is to explore experiences of AYAs who attended an IBD-tailored and developmentally informed MBCT group programme. A secondary objective is to investigate the role of common psychotherapy and group factors within the MBCT programme.

\section{METHODS}

\section{Study design}

This is a mixed methods qualitative study embedded within the randomised controlled trial (RCT) of an adapted MBCT programme for AYAs with IBD and depression. ${ }^{44}$ The study explored experiences of AYAs who participated in the MBCT programme. The study design adheres to the standards for reporting qualitative research ${ }^{45}$ and consolidated criteria for reporting qualitative research guidelines, ${ }^{46}$ as presented in online supplemental file 1 and the study protocol. ${ }^{47}$ Qualitative data were collected from focus groups and free-text questions from the post-MBCT evaluation survey. Two researchers analysed the data independently, using thematic analysis framework. ${ }^{48}$ Combining qualitative data from different data sources and using two researchers for coding and analysis enabled data and investigator triangulation.

\section{Participants, recruitment and sampling}

Participants for the study were recruited from the 64 participants in an RCT of MBCT for AYAs with IBD who completed the MBCT course and a post-MBCT evaluation survey. Recruitment commenced in June 2019, after the second MBCT group, to ensure sufficient participant numbers. Sampling for the focus groups was purposive and consecutive and continued until the researchers conducting thematic analysis agreed that no new relevant knowledge was being obtained indicating thematic saturation, which occurred after the third focus group, in December 2019. Twenty-nine participants returned the post-MBCT evaluation survey and nineteen took part in the three focus groups. Table 1 shows participants' basic demographic and clinical information.

\section{Focus groups}

Three focus groups were conducted in an outpatient facility, with seven participants attending each of the first two focus groups, and five participants attending the third, in keeping with the current guidelines for focus groups. ${ }^{49} 50$ Focus groups were conducted according 
Table 1 Participants basic demographic and clinical characteristics

\begin{tabular}{ll}
\hline Baseline & \\
\hline Age (years) (n, mean, SD) & $\begin{array}{l}\mathrm{n}=29, \\
\text { Mean age=21 (7.72) }\end{array}$ \\
\hline Gender F (n, \%), M (n, \%) & $\mathrm{F}=16(55.2 \%)$, \\
\hline Disease type & \\
\hline Crohn's disease (n, \%) & $19(65.8 \%)$ \\
\hline Ulcerative colitis (n, \%) & $10(34.5 \%)$ \\
\hline Marital status & \\
\hline Single (n, \%) & $16(55.2 \%)$ \\
\hline Committed relationship-not living & $5(17.2 \%)$ \\
together (n, \%) & $7(24.1 \%)$ \\
\hline Married/cohabitating (n, \%) & $1(3.5 \%)$ \\
\hline Divorced/separated (n, \%) & \\
\hline Education level & $5(17.2 \%)$ \\
\hline High school (n, \%) & $17(58.6 \%)$ \\
\hline Diploma (n, \%) & $7(24.2 \%)$ \\
\hline Degree or above (n, \%) & $13(44.8 \%)$ \\
\hline Current employment/education status \\
\hline Employed & $5(17.2 \%)$ \\
\hline Student & $11(38.0 \%)$ \\
\hline Not employed and studying & \\
\hline
\end{tabular}

to recommendations from Krueger and Casey's focus groups guide. ${ }^{51}$ They were run by the moderator and an assistant, with an observer behind the one-way mirror. The moderator $(\mathrm{AH})$ was a psychologist with training in qualitative research and experienced in running focus groups, the assistant was the study research assistant with a public health degree and the observer (TE) was the study principal investigator, a psychiatrist with training in qualitative research.

All three focus groups followed the same questioning route, summarised in Textbox 1 (see online supplemental file 2). Focus groups were audiotaped and transcribed verbatim. Participants were given the opportunity to review focus group transcripts and the preliminary results of thematic analysis and asked to comment and report any disagreements.

\section{Mindfulness-based cognitive therapy evaluation survey}

All participants who completed the course were asked to fill out the post-MBCT evaluation survey (see online supplemental file 3). The survey contains a mixture of closed and open-ended free-text questions exploring participants' experiences, perceived barriers and benefits of the programme and suggestions for improvement. As noted in previous research, combining qualitative data from focus groups and open-ended survey questions provided a rich dataset, enabled data triangulation ${ }^{32}$ and broader insights into participants' experiences. ${ }^{52}$

\section{Data analysis}

Qualitative data from focus groups and open-ended survey questions were analysed using thematic analysis, a flexible and rigorous qualitative research method for analysing and generating key themes and insights. ${ }^{48}$ An inductive thematic analysis approach was used given the exploratory nature of the study.

Two research team members (AH, TE), familiarised themselves with the data and individually and separately developed initial codes and themes, following the recommendations from Saldaña's Coding Manual for Qualitative Researchers. ${ }^{53}$ Coding was done manually, using double-spaced format and 'comments' function in Microsoft Word, which placed text in the left two-thirds of the page and created a wide right-hand margin for writing codes and notes. In the first coding cycle, the researchers independently developed and tested initial codes on the subsection of data, created a codebook and then discussed the initial codes and themes, rectifying any differences. In the second coding cycle, researchers continued to refine the codes, applied them to the full dataset and grouped them, looking for emerging relevant themes. The two researchers discussed the codes, categories and themes until they reached an agreement on the interpretation and continued to work with the data until no new themes were being identified, signalling thematic saturation.

\section{Reflexivity statement}

Research team members reflected throughout the study on the impact of their background, training, beliefs and relationship to the research topic and participants on the research process. Four of the research team members have medical training, three specialising in psychiatry (SK, MK, TE) and one in gastroenterology (JB), while two are allied health professionals, a psychologist (AH) and occupational therapist (MT). One of the researchers (TE) had lived experience of caring after a close family member with IBD. Three of the research team members have teacher training in MBCT and longstanding personal mindfulness practice (MK, MT, TE), one of them is the MBCT group facilitator (MT). One of the researchers who conducted thematic analysis (TE) was also involved in recruitment and observation of the focus groups which may have influenced participants' responses and researcher's observations and was mitigated by the researcher's and team reflexivity.

\section{Patient and public involvement}

Patients' views informed the study design and focus groups questioning guide. They were obtained during the study conception from AYAs from Mater Consumer Youth Consultancy Group members. Participants were not formally involved in recruitment or data analysis although many referrals came through recommendations from previous participants. Study findings will be 
disseminated to all participants as a lay summary, through this publication and presentations at consumer consultancy forums.

\section{RESULTS}

Four themes emerged from the analysis of the qualitative data from focus groups and free text survey questions: 'connectedness and shared understanding', 'growing in wisdom', 'therapeutic alliance' and 'barriers to mindfulness practice'. Thematic map illustrating the relationships between the key themes and subthemes is shown in online supplemental file 4 . All the key themes contained inter-related subthemes and corresponded to various common and group psychotherapeutic factors which is elaborated in the discussion section. Table 2 shows the list of all the key themes and subthemes and their representative quotes.

\section{Connectedness and shared understanding}

The theme of 'connectedness and shared understanding' contained three interlinked subthemes: "meeting and connecting', 'validation, practical and emotional support and understanding' and 'emerging hope'. Participants consistently spoke about the importance of connecting with peers and described mindfulness group as a vehicle for peer-to-peer connection. Table 1 in online supplemental file 5 shows connectedness and shared understanding quotes.

\section{Meeting and connecting}

Participants identified meeting and connecting with peers with IBD as one of the key benefits of the programme and a necessary foundation for practicing mindfulness, 'Like the mindfulness came second and the connection came first' (MIND 1). They described meeting and connecting with peers as an experience of freedom to express themselves, often after a long period of IBD-related isolation : 'a trial where you can actually be a person, so you feel freer to talk about your experiences in the trial itself. It helps us get the most out of the group, I think. It has been created for us. Because we're more like friends, not just colleagues' (MIND 25).

Validation, practical and emotional support and understanding Young people with IBD gave detailed accounts of validation, support and understanding that they experienced within the MBCT group. They often described these experiences as profound and yet easy and natural to them, making them feel supported and no longer alone: 'I think that it comes back to the validation where it's like it's confirmed, other young people have it, I'm not alone' (MIND 25).

Many participants contrasted the ease and spontaneity of support from their peers with mindfulness practices, which in their view, required more sustained effort. However, they felt that they needed and benefitted from both, 'I don't think you could have one without the
other-I feel like you need both, but I think meeting people is probably more of an immediate kind of a quick fix, it's just a great support, whereas the mindfulness is like tools that we have to learn and teach and we need to do work to make them work, whereas making friends isn't work' (MIND 28).

\section{Emerging hope}

A subtheme of emerging hope came both out of participants' direct reports of feeling more hopeful and indirect reports of a positive and hopeful outlook: 'it gave me the ability to enjoy life even with its difficulties' (MIND 42) and 'I learned how to appreciate the small things and how amazing life is' (MIND 37). They spoke about mindfulness as a 'gathering point where people could come together and talk about their experiences' (MIND 1) and how lucky they were to get the opportunity to practice mindfulness.

This was reflected in participants' posture and drawings on the evaluation survey such as multiple smiley faces or a unicorn.

\section{Growing in wisdom}

The theme 'growing in wisdom' emerged from a synthesis of participants' reported improvements following the programme. This included subthemes of 'healing and compassion', 'acceptance and mastery' and 'purpose and meaning'. Participants reported that their relationship with themselves, their condition and their environment changed as a result of attending the MBCT group. They described increased self-acceptance and compassion to others which they viewed as catalysts for healing. The MBCT group helped them find purpose and meaning within their difficulties. Table 2 in online supplemental file 6 shows the growing of wisdom quotes.

\section{Healing and compassion}

Most participants described a newfound sense of compassion and kindness towards themselves and others, "to have this ability to have a new insight on how to approach things with a more kind manner is a major step up for me' (MIND 42) and linked it with self-acceptance and acceptance of having IBD, 'I think the group actually helped me accept it a lot more, as well as what's going on with me and how that affects my life and other people' (MIND 18) and increased confidence in their ability manage their illness and general coping, 'I feel that I have tools to cope when life is challenging' (MIND 7). Participants' accounts highlighted the close links between the subthemes of 'healing and compassion', 'acceptance and mastery' and 'purpose and meaning' and how they worked together within the process of transformation and personal growth.

\section{Acceptance and mastery}

Overwhelmingly, participants gave detailed accounts of their changing perspectives and increased acceptance of their illness, themselves and their environment, 'I think the group actually helped me accept it a lot more as well as what's going on with me and how that affects my life 


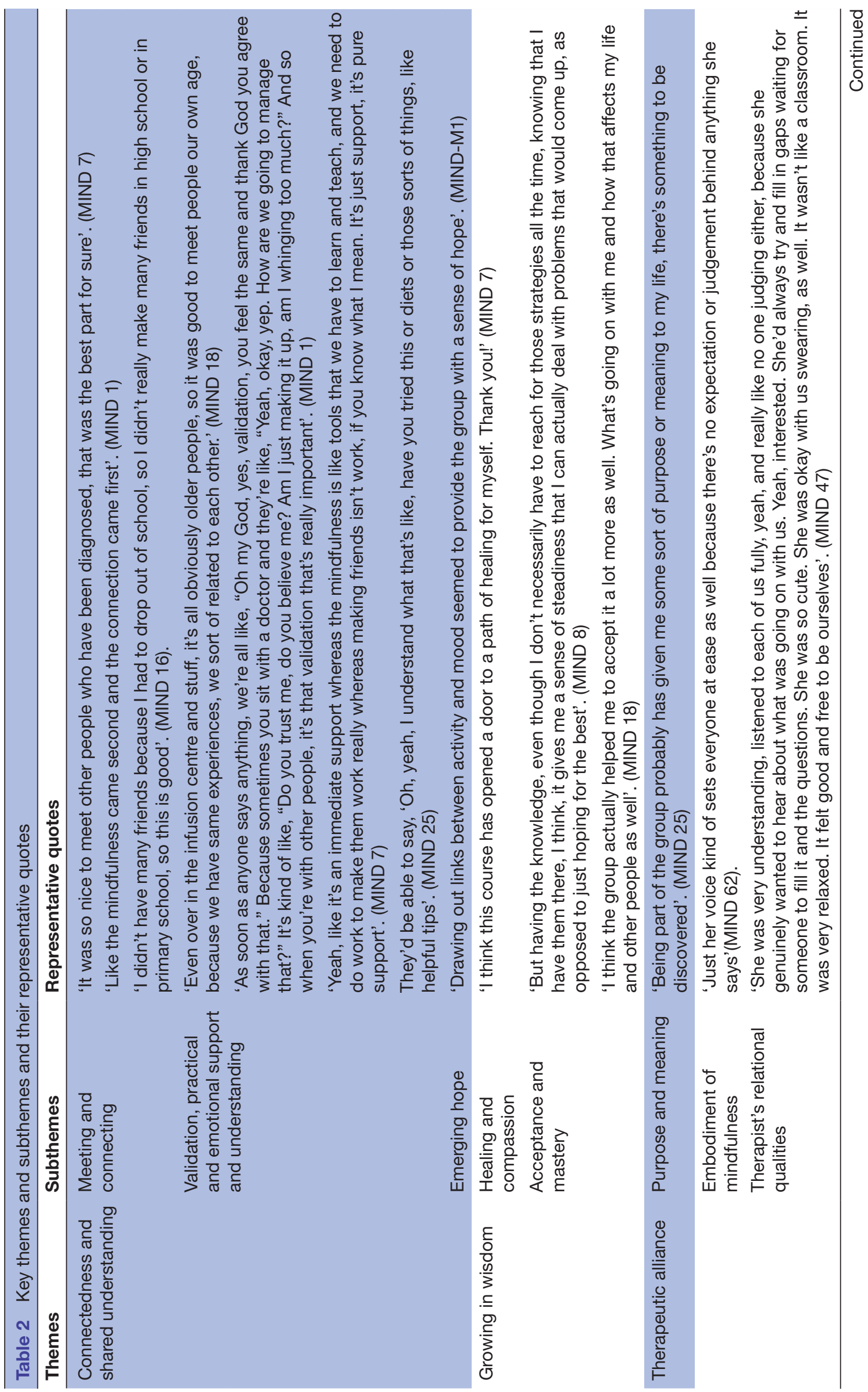




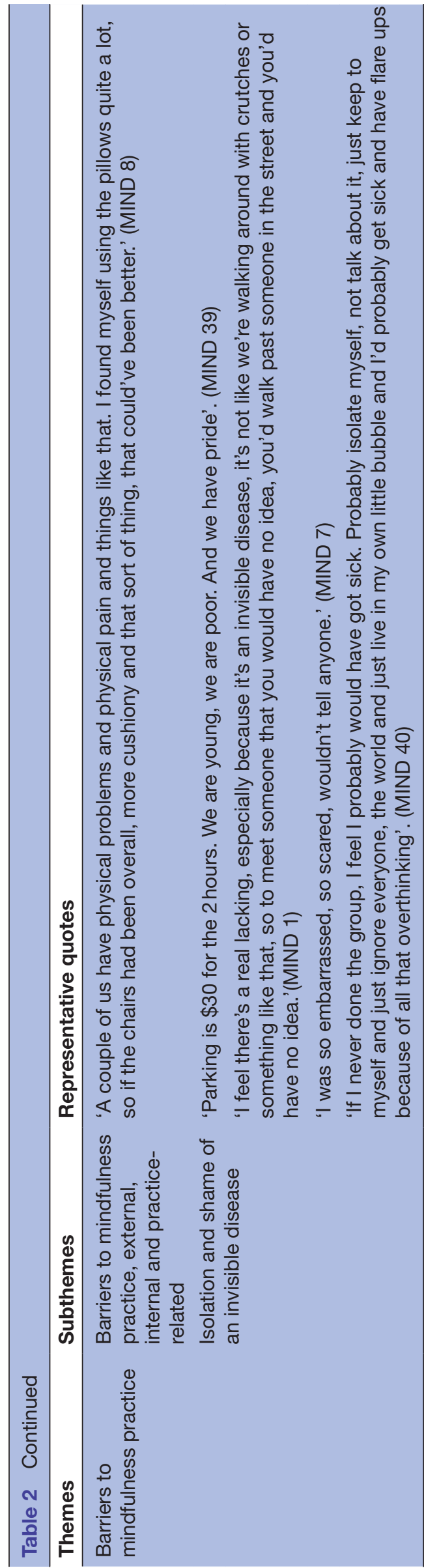

and other people' (MIND 18) and how this attitude of acceptance and 'allowing things to just be' (MIND 9) led to developing and mastery of new skills, 'I am more aware of my thoughts and feelings, I have noticed how I can slowly implement strategies into my life that can lead to mindful actions rather than emotional reactions' (MIND 27).

\section{Purpose and meaning}

Some participants reported that MBCT group helped them change their whole outlook on life, "I feel like it has helped me manage and take a different stance both on life and how to deal with certain situations' (MIND 1) and connect to their own sense of purpose and meaning, 'being part of the group probably has given me some sort of purpose or meaning to my life, there's something to be discovered' (MIND 25) and a sense that they were also a part of a larger community helping find new ways of treating IBD.

\section{Therapeutic alliance}

Participants reported that their relationship with the MBCT group facilitator and facilitator's qualities impacted positively on their group experience and their motivation to continue practicing. Therapeutic alliance emerged as one of the major themes, with subthemes of 'therapist's relational qualities' and 'embodiment of mindfulness'. Table 3 in online supplemental file 7 shows therapeutic alliance quotes.

\section{Therapist's relational qualities}

Participants spoke about facilitator's personal qualities of compassion and patience, but also conveyed their appreciation of the way she interacted with them, 'she was very approachable and warm, and I am appreciative that I never felt pressured to do anything I felt uncomfortable by; her insight and patience allowed me to give $100 \%$ effort into the session' (MIND 34).

\section{Embodiment of mindfulness}

Participants found that therapist's empathy, understanding and genuine interest were connected with her embodiment of mindfulness qualities which they felt engaged them and allowed them to express themselves freely, 'she was very understanding, listened to each of us fully, yeah, and really like no one judging either, because she genuinely wanted to hear about what was going on with us. Yeah, interested. She'd always try and fill in gaps waiting for someone to fill it and the questions. She was so cute. She was okay with us swearing, as well. It wasn't like a classroom. It was very relaxed. It felt good and free to be ourselves' (table 2, quote 14).

Many participants used humorous language and symbols to describe the facilitator such as 'Amazeballs!' (MIND 43) and reported that the facilitator was a good fit for the group, 'She was perfect for the course-Amazing woman!' and helped them transform their lives, 'She has really helped me change my life and I am so grateful to her' (MIND 28). 


\section{Barriers to mindfulness practice}

Barriers to ongoing mindfulness practices emerged as a key theme with the subthemes of 'internal, external and practice-related barriers' and 'isolation and shame of an invisible disease'. Table 4 in online supplemental file 8 shows the barriers to mindfulness practice quotes.

Participants identified low mood, overthinking, fatigue and pain as the most common internal barriers, 'Forgetfulness and legit depression were the barriers' (MIND $8)$. Lack of time was the main external barrier since the majority of participants were working or studying. Practice-related barriers included the length of the practices, 'the meditations that ran longer than 15 minutes were hard to follow for me. Still were helpful though' (MIND 59) and the type of formal practice, especially body scans, 'the really long body scans-too hard to focus for that long' (MIND 8). Interestingly, most of the participants found mindfulness of the breath helpful, especially the 3 min breathing space, and also informal mindfulness practices such as mindful walking.

Some participants reported travel time and parking costs as barriers. The majority identified isolation and embarrassing symptoms as barriers before starting the group, and being alleviated through attending the group, 'shame is like a big deal, but actually since joining the group, being less' (MIND 7).

\section{DISCUSSION}

This study examined experiences of AYAs with IBD who attended an MBCT group programme, and the role of common and group psychotherapy factors within the programme. While there have been numerous effectiveness studies of mindfulness interventions in IBD, this is the first study exploring MBCT experiences in AYAs with IBD and the first qualitative study investigating the role of common psychotherapy and group factors within MBCT.

The study findings indicate that AYAs with IBD highly value social connection and support provided by their peers and consider them essential for practicing mindfulness. This is aligned with mindfulness teaching philosophy of being taught in groups and conceptualised as experiential and relational with group members learning in relation to each other, in relation to the group and the teacher. ${ }^{54}$ It raises the question as to whether AYAs would get the same benefits if mindfulness skills were taught within the context of individual therapy. The importance of peer connection is reflected in the key theme of 'connectedness and shared understanding' and its subthemes which correspond to group factors of group cohesion, altruism, interpersonal learning, imparting knowledge and instilling hope. Our findings are supported by previous research showing that individuals suffering from IBD seek to share experiences with others who are affected by IBD, ${ }^{55}$ and a meta-synthesis of qualitative studies which identified the impact of the MBCT group as one of the key themes underlying therapeutic change. ${ }^{56}$ Our findings extend the MBCT group impact to include its specific components of validation, shared understanding and emerging hope and highlight their connection to group psychotherapeutic factors of group cohesion, socialisation, imparting knowledge and instilling hope.

We found that AYAs with IBD perceived the MBCT groups conducive to personal growth and transformation as depicted in the key theme of 'growing in wisdom' and its subthemes of 'healing and self-compassion', 'acceptance and mastery' and 'purpose and meaning' which correspond to the common factors of 'exposure and sense of mastery', 'enactment of adaptive actions' and 'existential factors'. These findings are in keeping with the themes of feeling towards the self, awareness and acceptance and taking control through understanding that were found in the meta-synthesis of qualitative studies examining the process of therapeutic change in MBCT in other patient groups. ${ }^{56}$ The findings are also supported by two recent systematic reviews of psychological mechanisms of MBCT that reported strong evidence for reducing cognitive and emotional reactivity and preliminary evidence for self-compassion. ${ }^{57}$ Our findings further elaborate on the MBCT factors of change in AYAs with IBD and link them to the corresponding common and group psychotherapeutic factors.

The study findings also demonstrate the importance of the therapeutic alliance in the MBCT group programme given participants consistently gave positive feedback about the group facilitator and her role in engaging them in mindfulness practices and facilitating their personal growth. These features of the facilitator and therapeutic relationship are reflected in the main theme of 'therapeutic alliance' and its subthemes of 'embodiment of mindfulness' and 'therapist's relational qualities' which are linked to mindfulness teaching competence factors of 'embodiment of mindfulness' and 'relational skills ${ }^{\text {,5 }} 59$ that belong to the six core competence domains and are considered crucial for the mindfulness-based teaching integrity. ${ }^{60}$ They correspond to the common factors of therapeutic alliance and therapist's effects.

Main barriers were participants' study and work commitments, their health issues, such as depression, and fatigue and practice-related factors. The barriers were somewhat different from the previous study of MBCT experiences in adults as AYAs placed more emphasis on the internal barriers followed by time constraints and practice-related barriers such as long formal practices especially body scans. They expressed strong preference for short formal practices such as the 3 min body scan and informal practices. These findings will help refine content of future MBCT programmes in AYAs with IBD with most pertinent adaptations involving shorter formal practices and encouragement of informal practices. Importantly, participants identified that IBD-related isolation and shame they experienced as barriers prior to joining the MBCT group were alleviated and reframed through the group participation. This extends previous research on the impact of shame and isolation in IBD population ${ }^{5561}$ 
and has both clinical and research implications as MBCTrelated alleviation of these symptoms is likely to lead to significantly improved quality of life in AYAs with IBD. Furthermore, they may benefit from recruitment strategies that are considering these symptoms and participating in MBCT groups that are specific to IBD youth.

These findings need to be considered in the context of the study limitations. One of the study limitations is related to the relatively small sample size potentially affecting the generalisability of results; however, given the study aims, specificity of the sample and a rich dataset, this sample size has been able to provide adequate information power about the phenomena explored and this patient group. ${ }^{62}$ Another limitation is related to one of the researchers conducting thematic analysis being involved in the recruitment and observation of the focus groups and potentially influencing the findings. This was mitigated by the data and investigator triangulation, participant checking of the focus group transcripts and the results of thematic analysis as well as researcher's and team reflexivity which strengthened the study validity.

\section{CONCLUSION}

This qualitative study of MBCT experiences and common and group factors within an adapted MBCT group programme for youth with IBD found MBCT to be well accepted and perceived as effective. The core themes of connectedness and shared understanding, growing in wisdom and therapeutic alliance were linked to the corresponding common and group therapy factors. The study identified key barriers to ongoing mindfulness practice in AYAs with IBD and their key clinical and research implications, thus contributing to the clinical applicability of MBCT in this population. The study findings will facilitate interpretation of the results of the RCT of MBCT in AYAs with IBD and help inform the design of future larger studies of MBCT in this patient cohort.

\section{Twitter Tatjana Ewais @tatjanaewais}

Acknowledgements The authors would like to thank the Mater Youth Consultancy Group members for their input in the study conception and design and Ms Anne Tremellen, Ms Frances Maguire, Mr Ben Karagiannakis, Ms Jodie Deans, Ms Angela Pearson and Ms Arianna Safi from Mater Research for their support during the study.

Contributors The study was conceived and designed by TE and critically revised by SK, JB, MK, AH and MT. Drafting of the paper was completed by TE. All authors edited the manuscript.

Funding This work was supported by a grant from the Brain Injured Children's Aftercare Recovery Endeavours. They had no role in the data collection, interpretation or reporting.

Competing interests None declared.

Patient consent for publication Not required.

Ethics approval The study was approved by the Mater Hospital Human Research Ethics Committee.

Provenance and peer review Not commissioned; externally peer reviewed.

Supplemental material This content has been supplied by the author(s). It has not been vetted by BMJ Publishing Group Limited (BMJ) and may not have been peer-reviewed. Any opinions or recommendations discussed are solely those of the author(s) and are not endorsed by BMJ. BMJ disclaims all liability and responsibility arising from any reliance placed on the content. Where the content includes any translated material, BMJ does not warrant the accuracy and reliability of the translations (including but not limited to local regulations, clinical guidelines, terminology, drug names and drug dosages), and is not responsible for any error and/or omissions arising from translation and adaptation or otherwise.

Open access This is an open access article distributed in accordance with the Creative Commons Attribution Non Commercial (CC BY-NC 4.0) license, which permits others to distribute, remix, adapt, build upon this work non-commercially, and license their derivative works on different terms, provided the original work is properly cited, appropriate credit is given, any changes made indicated, and the use is non-commercial. See: http://creativecommons.org/licenses/by-nc/4.0/.

\section{ORCID iDs}

Tatjana Ewais http://orcid.org/0000-0002-1136-0605

Steve Kisely http://orcid.org/0000-0003-4021-2924

\section{REFERENCES}

1 Abraham C, Cho JH. Inflammatory bowel disease. N Engl J Med 2009;361:2066-78

2 Bernstein CN, Hitchon CA, Walld R, et al. Increased burden of psychiatric disorders in inflammatory bowel disease. Inflamm Bowel Dis 2019;25:360-8.

3 Neuendorf R, Harding A, Stello N, et al. Depression and anxiety in patients with inflammatory bowel disease: a systematic review. $J$ Psychosom Res 2016;87:70-80.

4 Marrie RA, Walker JR, Graff LA, et al. Performance of administrative case definitions for depression and anxiety in inflammatory bowel disease. J Psychosom Res 2016;89:107-13.

5 Taft TH, Bedell A, Craven MR, et al. Initial assessment of posttraumatic stress in a US cohort of inflammatory bowel disease patients. Inflamm Bowel Dis 2019;25:1577-85.

6 Villoria A, García V, Dosal A, et al. Fatigue in out-patients with inflammatory bowel disease: prevalence and predictive factors. PLOS One 2017;12:e0181435.

7 Zeitz J, Ak M, Müller-Mottet S, et al. Pain in IBD patients: very frequent and frequently Insufficiently taken into account. PLoS One 2016;11:e0156666.

8 Martin-Subero M, Anderson G, Kanchanatawan B, et al. Comorbidity between depression and inflammatory bowel disease explained by immune-inflammatory, oxidative, and nitrosative stress; tryptophan catabolite; and gut-brain pathways. CNS Spectr 2016;21:184-98.

9 Edman JS, Greeson JM, Roberts RS, et al. Perceived stress in patients with common gastrointestinal disorders: associations with quality of life, symptoms and disease management. Explore 2017;13:124-8.

10 Mikocka-Walus A, Pittet V, Rossel J-B, et al. Symptoms of depression and anxiety are independently associated with clinical recurrence of inflammatory bowel disease. Clin Gastroenterol Hepatol 2016;14:829-35.

11 Keefer L, Kane SV. Considering the bidirectional pathways between depression and IBD: recommendations for comprehensive IBD care. Gastroenterol Hepatol 2017;13:164-9.

12 Bonaz BL, Bernstein CN. Brain-gut interactions in inflammatory bowel disease. Gastroenterology 2013;144:36-49.

13 Breit S, Kupferberg A, Rogler G, et al. Vagus nerve as modulator of the brain-gut axis in psychiatric and inflammatory disorders. Front Psychiatry 2018;9:44.

14 Caspani G, Kennedy S, Foster JA, et al. Gut microbial metabolites in depression: understanding the biochemical mechanisms. Microb Cell 2019;6:454-81

15 Sun Y, Li L, Xie R, et al. Stress triggers flare of inflammatory bowel disease in children and adults. Front Pediatr 2019;7:432.

16 de Souza HSP, Fiocchi C, lliopoulos D. The IBD interactome: an integrated view of aetiology, pathogenesis and therapy. Nat Rev Gastroenterol Hepatol 2017;14:739-49.

17 Mayer EA, Tillisch K, Gupta A. Gut/Brain axis and the microbiota. $J$ Clin Invest 2015;125:926-38.

18 Szigethy EM, Allen JI, Reiss M, et al. White paper AGA: the impact of mental and psychosocial factors on the care of patients with inflammatory bowel disease. Clin Gastroenterol Hepatol 2017;15:986-97.

19 Johnston RD, Logan RFA. What is the peak age for onset of IBD? Inflamm Bowel Dis 2008;14 Suppl 2:S4-5. 
20 Cosnes J, Gower-Rousseau C, Seksik P, et al. Epidemiology and natural history of inflammatory bowel diseases. Gastroenterology 2011;140:1785-94.

21 Greenley RN, Hommel KA, Nebel J, et al. A meta-analytic review of the psychosocial adjustment of youth with inflammatory bowel disease. J Pediatr Psychol 2010;35:857-69.

22 Crane RS, Brewer J, Feldman C, et al. What defines mindfulnessbased programs? the warp and the weft. Psychol Med 2017;47:990-9.

23 Black DS, Slavich GM. Mindfulness meditation and the immune system: a systematic review of randomized controlled trials. Ann NY Acad Sci 2016;1373:13-24.

24 Ewais T, Begun J, Kenny M, et al. A systematic review and meta-analysis of mindfulness based interventions and yoga in inflammatory bowel disease. J Psychosom Res 2019;116:44-53.

25 Sanada K, Montero-Marin J, Barceló-Soler A, et al. Effects of mindfulness-based interventions on biomarkers and low-grade inflammation in patients with psychiatric disorders: a meta-analytic review. Int J Mol Sci 2020;21. doi:10.3390/ijms21072484. [Epub ahead of print: 03 Apr 2020].

26 Crowe M, Jordan J, Burrell B, et al. Mindfulness-based stress reduction for long-term physical conditions: a systematic review. Aust N Z J Psychiatry 2016;50:21-32.

27 Schoultz M. The use of mindfulness-based cognitive therapy for patients with inflammatory bowel disease. USA: ProQuest Dissertations Publishing, 2016.

28 Neilson K, Ftanou M, Monshat K, et al. A controlled study of a group mindfulness intervention for individuals living with inflammatory bowel disease. Inflamm Bowel Dis 2016;22:694-701.

29 Segal ZV, Williams JMG, Teasdale JD. Mindfulness-based cognitive therapy for depression. 2 edn. New York: The Guilford Press, 2013.

30 Schoultz M, Atherton I, Watson A. Mindfulness-based cognitive therapy for inflammatory bowel disease patients: findings from an exploratory pilot randomised controlled trial. Trials 2015;16:379.

31 Ahola Kohut S, Stinson J, Jelen A, et al. Feasibility and acceptability of a Mindfulness-Based group intervention for adolescents with inflammatory bowel disease. J Clin Psychol Med Settings 2020;27:68-78.

32 Schoultz M, Macaden L, Hubbard G. Participants' perspectives on mindfulness-based cognitive therapy for inflammatory bowel disease: a qualitative study nested within a pilot randomised controlled trial. Pilot Feasibility Stud 2016;2:3.

33 Wampold BE. How important are the common factors in psychotherapy? an update. World Psychiatry 2015;14:270-7.

34 Weinberger J. Common factors are not so common and specific factors are not so specified: toward an inclusive integration of psychotherapy research. Psychotherapy 2014;51:514-8.

35 Drisko JW. Common factors in psychotherapy outcome: metaanalytic findings and their implications for practice and research. Families in Society 2004;85:81-90.

36 Rosenzweig S. Some implicit common factors in diverse methods of psychotherapy. Am J Orthopsychiatry 1936;6:412-5.

37 Weinberger J. Common factors aren't so common: the common factors dilemma. Clini Psy 1995;2:45-69.

38 Yalom ID, Leszcz M. The theory and practice of group psychotherapy. 5th ed. New York: Basic Books, 2005.

39 Sugarman DE, Wigderson SB, lles BR, et al. Measuring affiliation in group therapy for substance use disorders in the women's recovery group study: does it matter whether the group is all-women or mixed-gender? Am J Addict 2016;25:573-80.

40 Diefenbeck CA, Klemm PR, Hayes ER. Emergence of Yalom's therapeutic factors in a peer-led, asynchronous, online support group for family caregivers. Issues Ment Health Nurs 2014;35:21-32.

41 Kabat-Zinn J. Full catastrophe living: using the wisdom of your body and mind to face stress, pain, and illness. In: Kabat-Zinn J, ed. C. University of Massachusetts medical center/worcester. Stress reduction. New York: Dell Publishing, 1991.

42 Martin JR. Mindfulness: a proposed common factor. J Psychother Integr 1997:7:291-312.

43 Day MA, Halpin J, Thorn BE. An empirical examination of the role of common factors of therapy during a Mindfulness-based cognitive therapy intervention for headache pain. Clin J Pain 2016;32:420-7.

44 Ewais T, Begun J, Kenny M, et al. Protocol for a pilot randomised controlled trial of mindfulness-based cognitive therapy in youth with inflammatory bowel disease and depression. BMJ Open 2019;9:e025568.

45 O'Brien BC, Harris IB, Beckman TJ, et al. Standards for reporting qualitative research: a synthesis of recommendations. Acad Med 2014;89:1245-51.

46 Tong A, Sainsbury P, Craig J. Consolidated criteria for reporting qualitative research (COREQ): a 32-item checklist for interviews and focus groups. Int J Qual Health Care 2007;19:349-57.

47 Ewais T, Begun J, Kenny M, et al. Mindfulness-based cognitive therapy experiences in youth with inflammatory bowel disease and depression: protocol for a mixed methods qualitative study. JMIR Res Protoc 2019;8:e14432.

48 Braun V, Clarke V. Using thematic analysis in psychology. Qual Res Psychol 2006;3:77-101.

49 Barbour RS. Making sense of focus groups. Med Educ 2005;39:742-50.

50 Barbour R, Groups DFBarbour R, ed. Doing focus groups. London, UK: SAGE Publications Ltd, 2007.

51 Krueger RA, Casey MA. Focus groups : a practical guide for applied research. 5th edition. Thousand Oaks, California: SAGE, 2015.

52 Garcia J, Evans J, Reshaw M. "Is there anything else you would like to tell us" - methodological issues in the use of free-text comments from postal surveys. Qual Quant 2004;38:113-25.

53 Saldaña J. The coding manual for qualitative researchers. London: SAGE, 2009.

54 Griffith GM, Bartley T, Crane RS. The inside out group model: teaching groups in mindfulness-based programs. Mindfulness 2019;10:1315-27.

55 Purc-Stephenson R, Bowlby D, Qaqish ST. "A gift wrapped in barbed wire" positive and negative life changes after being diagnosed with inflammatory bowel disease. Qual Life Res 2015;24:1197-205

56 Cairns V, Murray C. How do the features of mindfulness-based cognitive therapy contribute to positive therapeutic change? A meta-synthesis of qualitative studies. Behav Cogn Psychother 2015;43:342-59.

57 Gu J, Strauss C, Bond R, et al. How do mindfulness-based cognitive therapy and mindfulness-based stress reduction improve mental health and wellbeing? A systematic review and meta-analysis of mediation studies. Clin Psychol Rev 2015;37:1-12.

58 Crane RS, Eames C, Kuyken W, et al. Development and validation of the mindfulness-based interventions - teaching assessment criteria (MBI:TAC). Assessment 2013;20:681-8.

59 Huijbers MJ, Crane RS, Kuyken W, et al. Teacher competence in mindfulness-based cognitive therapy for depression and its relation to treatment outcome. Mindfulness 2017;8:960-72.

60 Crane RS, Kuyken W. The mindfulness-based interventions: teaching assessment criteria (MBI:TAC): reflections on implementation and development. Curr Opin Psychol 2019;28:6-10.

61 Saunders B. Stigma, deviance and morality in young adults accounts of inflammatory bowel disease. Sociol Health IIIn 2014;36:1020-36.

62 Malterud K, Siersma VD, Guassora AD. Sample size in qualitative interview studies: guided by information power. Qual Health Res 2016;26:1753-60. 